\title{
The effect of strength parameters on the seismic performance of an arch dam using an uncertainty model
}

\author{
Majid Pasbani Khiavi* ${ }^{* 1}$, Parya Ahmadi ${ }^{1}$, Rasoul Daneshfaraz ${ }^{(1)}$, John Abraham ${ }^{3}$ \\ Faculty of Engineering, University of Mohaghegh Ardabili, Ardabil (Iran) \\ Faculty of Civil Engineering, University of Maragheh, Maragheh, East Azarbaijan (Iran) \\ University of St. Thomas, St Paul, MN (USA) \\ *Correspondence: pasbani@uma.ac.ir
}

Received: 01.04.2021; Accepted: 13.11.2021; Published: 31.12.2021

Citation: Pasbani Khiavi, M., Ahmadi, P., Daneshfaraz, R., and Abraham, J. (2021). Manuscript title. Revista de la Construcción. Journal of Construction, 20(3), 602-616. https://doi.org/10.7764/RDLC.20.3.602.

\begin{abstract}
Considering the importance of the effect of concrete arch dam body strength on their seismic performance, this research evaluated the effect of Young Modulus of both the body concrete and foundation as strength parameters and examines the responses to achieve the optimal body stiffness using probabilistic and uncertainty method. The ANSYS software was used to complete the finite element analysis of the dam-reservoir-foundation system and the Monte Carlo method, which is a new method for parametric study and sensitivity analysis, was used for uncertainty analysis. For seismic analysis, the horizontal and vertical components of Northridge, San Fernando and El Centro earthquakes are separately applied in $3 \mathrm{~d}$ directions. The earthquake components were scaled to the maximum credible level of ground motion acceleration. The foundation rock is simulated using a massless foundation model and dam-reservoir-foundation interaction is considered for seismic analysis of system. The results show the effect of the modulus of elasticity of the concrete which is directly related to the stiffness of the system. The results indicate the effect of the dam body concrete stiffness on the responses. According to the design criteria, it is possible to investigate the safety status of the dam and select the optimal state in terms of structural strength for the model. However, in order to properly select the modulus of elasticity of the concrete of the dam body, it is necessary to consider the simultaneous effect of the stiffness of the foundation and to select the optimal value.
\end{abstract}

Keywords: arch dam, probabilistic analysis, Monte-Carlo simulation, Young modulus, modulus ratio, finite element method

\section{Introduction}

Arch dam-foundation-reservoir system is important civil infrastructures. The behaviour of each part of this system affects the dam's seismic behaviour. There are several parameters which affect a concrete arch dam such as the interaction between the dam-reservoir-foundation system, the compressibility of water, the applied loads, the size of the foundation and the properties of the construction materials (Chopra, 2012). The effect of the characteristics of the bedrock on the behavior of the dam is an important topic for researchers. The seismic response of an arch dam is affected by the dam-reservoir and damfoundation interactions, damping, and the characteristics of the earthquake. Dam-water-foundation interactions have been studied by Tan and Chopra (1996) who used finite and boundary element methods to simulate the dam-water-foundation system. The added-mass concept of the dam-water interaction during earthquake ground motion was first introduced by 
Westergaard (1933). A wider form of the Westergaard added-mass can be used to perform the seismic analysis of arch dams (Kuo, 1982).

The dam-reservoir interaction related to water compressibility has been introduced by researchers such as Fok et al. (1986), Hariri-Ardebili et al. (2013) and Heshmati et al. (2013). The actual assessment of the seismic behaviour is obtained by investigating the effects of the parameters used in the analysis (National Academy Press, 1990 and Applied Technology Council (ATC), 2012). The seismic performance of the system considering interaction effects is dependent on variable parameters such as the physical properties of concrete. Parameters used in design and analysis include unit weight, Poisson's ratio, Young's modulus, the thermal expansion coefficient, and the tensile, compressive, and shear strengths.

An accurate evaluation of hydrodynamic pressure on a dam should consider the effect of bedrock flexibility which associated with the modulus of elasticity. Thus, the effect of foundation rock flexibility should be considered to assess the hydrodynamic pressure on the dam body. Other researchers have assessed the effects of the flexibility of the dam body and the bed rock on the behaviour of dams (Ferdousi, et al., 2014). Leger and Boughoufalah (1989) evaluated the effects of four parameters related to the local soil conditions on the seismic performance of systems. The four parameters were: (1) the models of the standard rigid base, (2) the mass-less foundation, (3) the de-convolved base-rock and (4) the free-field interface of the dam foundation. But in all of the studies, there are many sources of uncertainty that affect the responses of systems. Probability analysis is one of the techniques that can incorporate uncertainty and variability into risk analysis. Probabilistic analyses include methods that can be employed to address both uncertainty and variability, typically due to limited data, incomplete models, or inadequate formulation of the scenarios (Altarejos, 2012).

Examining the seismic behaviour of dams which are widely built in seismic zones is important for the safety and longevity of these systems. It is necessary to study the effects of earthquakes on dams. In recent years, some research has been done on this topic. The research has been shown that far fault earthquakes have important effects on the seismic damage and the nonlinear principal stress behaviour of dams, similar to near field earthquakes. Also, it is seen that far fault earthquakes should not be ignored in modelling and analysing procedure, because these earthquakes are the main cause of seismic damage. Some research indicates that the epicentre distance of the earthquakes affects the nonlinear behaviour of dams under seismic loads. Another study shows that horizontal and vertical displacements and principal stresses for full reservoir exceed those of empty reservoirs. In a probabilistic model, uncertainty in the response can be quantified by considering the effects of uncertainties. For seismic analysis of structures, randomness due to natural ground motion, record variability, and uncertainty stemming from modelling assumptions, omissions or errors are causes of uncertainty (U.S. Environmental Protection Agency, 2014). Theoretical and numerical methods are used for dynamic analysis of concrete dams because the laboratory studies are so expensive and limited in their ability to adequately capture real-world behavior (Rohaninejad and Zarghami, 2012). The Monte Carlo method is an efficient means for estimating probability distribution outputs of a model (Cullen and Frey, 1999, Morgan, et al. 1992). Monte Carlo methods are mainly used in optimization problems. A Monte Carlo simulation can be improved through Latin Hypercube Sampling described by McKay et al. (2000). This method involves the generation of random events. This process has a memory, which means the sampling points are not clustered together (Risk assessment forum U.S, 1997).

Pasbani Khiavi et al. (2020) used the Monte Carlo probabilistic analysis capability to investigate the effect of the reservoir length on the seismic performance of concrete gravity dam and examined the trend of changes in responses according to the effects of reservoir length. Following the investigation, Pasbani Khiavi et al. (2020) used the Monte Carlo probabilistic method with Latin Hypercube Sampling method for seismic optimization of the concrete gravity dam using an upstream rubber damper. Using sensitivity and uncertainty analyses, they obtained the optimal dimensions of the rubber damper to control the hydrodynamic pressure due to the interaction between the dam and reservoir. Pasbani Khiavi et al. (2021) also evaluated the effect of Young Modulus of body concrete and foundation as strength parameters on seismic performance of elevated tanks and examines the responses for optimization of seismic behaviour and safety design. In this paper, a model is formulated to show the effect of changes in body stiffness and the ratio of the body concrete stiffness to the foundation on the seismic response of an arch dam. In this article, the dam-reservoir-foundation system was studied using a probabilistic analysis to show the sensitivity of seismic performance of an arch dam to the strength of the dam and foundation, the modulus ratio of 
the foundation to the concrete, and Young's modulus for concrete. Based on the results, the optimal value for the modulus of elasticity of concrete can be identified. Other applications of the proposed probabilistic model include its ability to analyze arch dam and reservoir systems with heterogeneous foundations. The number of samples $(\mathrm{N})$ for the probabilistic simulation is 30 . The scaled components of the selected earthquake ground motions have been applied to the system to provide seismic analysis of the model. For seismic sensitivity analysis ANSYS FEM software and Monte Carlo probabilistic analysis are applied as a suitable optimization method. ANSYS is a software program based on the finite element method and is used to give more accurate results for complicated geometries. In the finite element method, the geometry is divided into small parts and the boundary conditions are applied. Finally the results are obtained for each node or element. ANSYS software is capable of seismic analysis and Monte Carlo probabilistic simulation. The Latin Hypercube Sampling (LHS) method is used in Monte Carlo probabilistic analysis. For seismic analysis, the dam-reservoir-foundation interaction is considered and the massless model is used for the flexible foundation. The flexibility of the foundation is considered in the simple massless model, while the effects of inertia are neglected.

\section{Methodology}

Most of the engineers, who utilize from general sophisticated software packages to structural analysis, often have no access to general sophisticated software packages and even don't have enough knowledge about the details of structure analysis's algorithms have been used in these soft wares. Therefore, the main challenge of structural optimization researchers is to regulate approaches and methods proper to such kind of soft wares. Another main challenge is high computing costs of analysis of infrastructures such as concrete dams. One of the modern approaches of structures optimization is utilizing the Monte Carlo probabilistic analysis. In present research, Monte Carlo probabilistic analysis with ANSYS Software has been used to optimize the seismic behaviour of an arch dam. For probabilistic Monte Carlo simulation the Latin Hypercube Sampling (LHS) method is used. It must be mentioned that ANSYS software is capable for probabilistic analysis with LHS method.

In Monte Carlo simulation, a random number is determined, and then the likelihood of an event is compared with the randomly generated number. In the case where the generated number meets the probability criterion, a process or set of processes or developments occurs in the next section. This procedure can be repeated several times, and a measurable output can be generated for each repetition. In the final section, the set of experiments or outcomes are processes statistically, and an understandable and interpretable quantity is reported. The process part with events can be simple or very complex and may contain many loops and algorithms and even multiple random generators. Besides, it is possible to extract quantitative data from any point of the algorithm and analyze them as output variables. Monte Carlo simulation methods can be used in all fields of science and engineering to predict the real and virtual behaviour of systems and define different scenarios. Latin hypercube sampling may be viewed as a stratified sampling scheme designed to ensure that the upper or lower ends of the distributions used in the analysis are well represented. Latin hypercube sampling is generally recommended over Direct Sampling method when the model is complex or when time and resource constraints are an issue. The nature of LHS does not determine the appropriate sample size to achieve a certain confidence level. There is no specified value for sample size $\mathrm{N}$ to achieve a certain confidence level in LHS (Vamvatsikos and Fragiadakis, 2010).

By sampling $\mathrm{N}$ times from the parameter distributions, this procedure creates a population of $\mathrm{N}$ possible instances of the structure, each of which needs to be analyzed. The use of relatively high $\mathrm{N}$ that is at substantially larger than the number of parameters will always result to reasonably accurate estimates for practical purposes. The optimal $\mathrm{N}$ to use is a function of the number of random variables and their influence on the response. The basis for all LHS simulation steps is generating random numbers being uniformly distributed between 0 and 1 . When there is an understanding of $U$ is related to the uniform distribution of random number $\mathrm{U}$ between 0 and 1, it is possible to produce $\mathrm{x}$ related to the uniform distribution of random number $\mathrm{x}$ between both values $\mathrm{a}$ and $\mathrm{b}(\mathrm{a} \leq \mathrm{x} \leq \mathrm{b})$. The process part with events can be simple or very complex and may contain many loops and algorithms and even multiple random generators. Besides, it is possible to extract quantitative data from any point of the algorithm and analyze them as output variables. Monte Carlo simulation methods can be used in all fields of science and engineering to predict the real and virtual behaviour of systems and define different scenarios. 


\section{Governing equations of system}

The problem is formulated in terms of both the structural and hydrodynamic phenomena. The governing equation of solid body motion, including damping effects is given by:

$$
M \ddot{X}+C \dot{X}+K X=M \ddot{X}_{g}+F_{P}
$$

The symbols $M, C$, and $K$ are the mass, damping, and stiffness matrices for a coupled system. The damping matrix is related to the mass and stiffness matrix according to the Rayleigh method (Chakrabati and Chopra, 1973). The symbols $X, \dot{X}$ and $\ddot{X}$ are the displacement, velocity, and acceleration of the coupled system and the symbol $F_{P}$ is the hydrodynamic pressure at the solid-water interface which is obtained by integrating the pressure over the area of the surface (Bathe, 1996, Hall and Chopra 1982, Sharan and Gladwell, 1985). Using the continuity equation for inviscid, compressible and irrotational flow with small amplitude motions, the three-dimensional form of Helmholtz equation for hydrodynamic pressure can be written as:

$$
\frac{\partial^{2} P}{\partial x^{2}}+\frac{\partial^{2} P}{\partial y^{2}}+\frac{\partial^{2} P}{\partial z^{2}}=\frac{1}{C^{2}} \frac{\partial^{2} P}{\partial t^{2}}
$$

where $P$ is the hydrodynamic pressure and $C$ is the acoustic wave velocity in water, $x, y$ and $z$ are the Cartesian coordinates and $t$ is time. With a Sommerfeld boundary condition at the far field of the reservoir boundary, the boundary condition at the dam-water interface can be expressed as:

$$
\frac{\partial P}{\partial n}=-\rho_{w} a_{n}
$$

where $a_{n}$ is normal component of boundary acceleration and $\rho_{w}$ is the water density. A Sommerfeld boundary condition is considered at the far field of the reservoir boundary and the effect of pressure at reservoir free surface is neglected. In order to determine the sensitivity of the output parameters to the inputs, simulations will account for the ratio of the Young's modulus of the foundation $\left(E_{f}\right)$ to that of the concrete dam $\left(E_{c}\right)$.

\section{Description of the case study}

The Morrow Point double curvature arch dam has been selected as an ideal model with a symmetric geometry. The height of model is about $142 \mathrm{~m}$. The length of the crest, the maximum thickness of the dam at the top and base are $184 \mathrm{~m}, 3.66 \mathrm{~m}$ and $15.73 \mathrm{~m}$, respectively. The inner radius of the arch at the crest level and zero level of dam are $114.30 \mathrm{~m}$ and $71.57 \mathrm{~m}$, respectively. To dissipate the effects of the end of the system, the length of the reservoir is 3 times bigger than the dam height, and the reservoir is modelled with a fixed-section prismatic shape. The height, width, and length of the foundation have been considered as twice of the dam height. To dissipate the total hydrodynamic wave effect, boundary conditions are applied at the end of the reservoir. The assumed pressure at the top level of the reservoir is zero. 


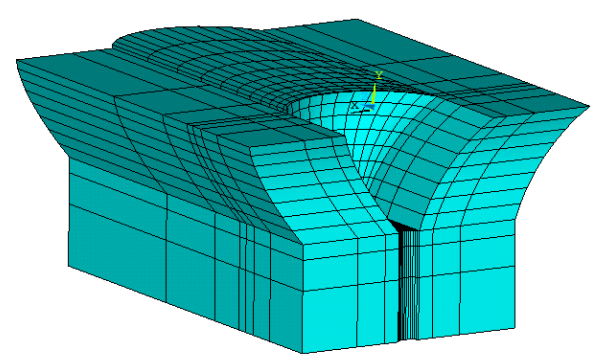

Figure 1. Finite element model of the system

The system is analyzed using ANSYS software which is based on the finite element method. There are 134 eight-node SOLID45 elements, for the dam body, 734 SOLID45 elements are used for the foundation rock, and 875 eight-node FLUID30 elements constitute the reservoir domain. The FLUID30 elements have three degrees of freedom for fluid motion and one degree of freedom for pressure. The selected solid and fluid elements reveal a three-dimensional curvilinear geometry of the dam and compressibility fluid in the reservoir model, respectively. The standard Newmark method is applied to solve the dynamic equation time history analysis. $\gamma_{1}=0.25$ and $\gamma_{2}=0.5$ are the Newmark parameters and $\Delta \mathrm{t}=0.02$ sec is the time integration step for selected motion. The damping ratio of the dam and foundation is assumed to be 5\%. Table 1 shows the material properties of model.

Table 1. Material properties of system.

\begin{tabular}{lll}
\hline Property & Dam & Foundation \\
\hline Weight $\left(\mathrm{N} / \mathrm{m}^{3}\right)$ & 24800 & 26430 \\
Modulus of elasticity $(\mathrm{GPa})$ & 27.5 & 22 \\
Poison ratio & 0.2 & 0.2 \\
\hline
\end{tabular}

The water density and acoustic velocity of water are assumed $1000 \mathrm{~kg} / \mathrm{m} 3$ and $1440 \mathrm{~m} / \mathrm{s}$, respectively. The displacement of the dam crest along the river and the first and third principal stresses are selected as output parameters and the Young's modulus and the modulus ratio of the foundation to the concrete are chosen to be input parameters. The Northridge (LABaldwin Hills station) and San-Fernando (Pacoima Dam station) earthquakes have been applied to the model in horizontal, cross-stream, and vertical components. Figures 2 to 4 demonstrate the initial 10 seconds of selected earthquake acceleration components.

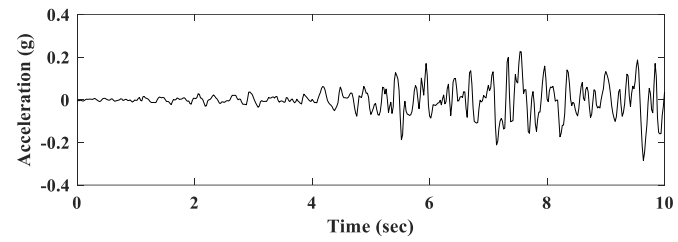

(a)

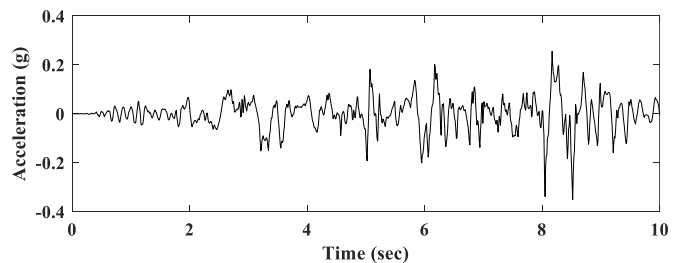

(b)

Figure 2. Streamwise component of acceleration; (a) Northridge; (b) San-Fernando.

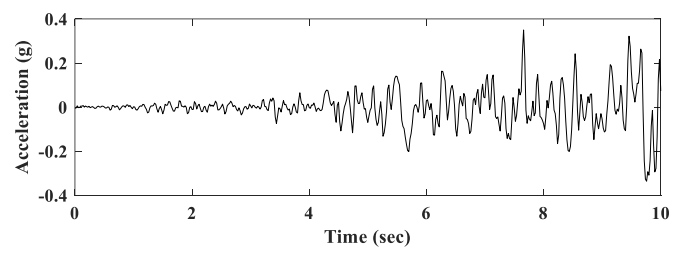

(a)

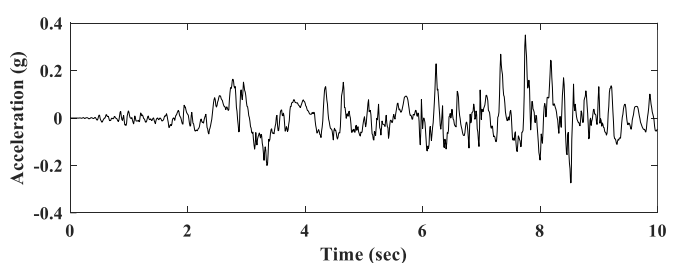

(b)

Figure 3. Cross-Stream component of acceleration; (a) Northridge; (b) San-Fernando. 


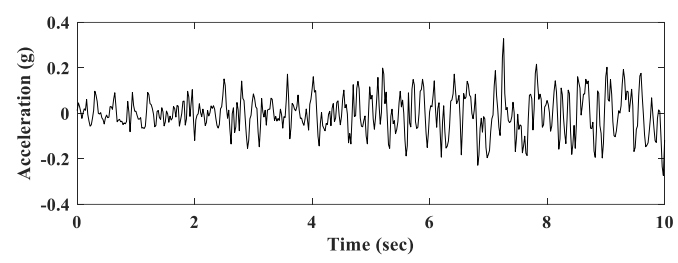

(a)

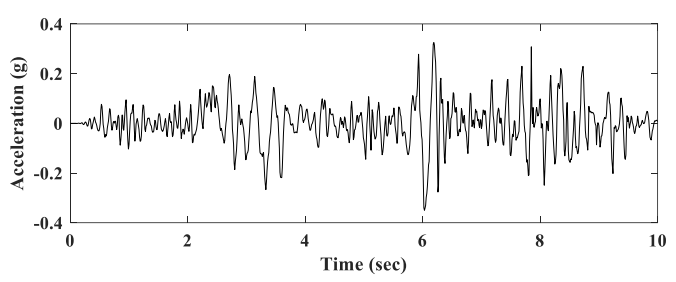

(b)

Figure 4. The vertical component of acceleration; (a) Northridge, (b) San-Fernando

In this research, the finite element method is used for seismic analysis of arch dam model considering variation in strength parameters. The components of selected earthquakes are applied to the entire body of the system to perform seismic performance of the studied model according to the ANSYS software capabilities. For probabilistic analysis, the number of required simulations should be such that the average value of the output variable reaches the appropriate convergence according to the number of simulations. So, in this study the ANSYS software settings are selected for Monte Carlo probabilistic method according to Table 2 .

Table 2. Monte Carlo probabilistic analysis settings in ANSYS software

\begin{tabular}{llll}
\hline Number simulation loops & Distribution type & Random variable & Number of iterations \\
\hline Modulus of elasticity & Lognormal & 30 & 2 \\
Modulus ratio & Lognormal & 30 & 2 \\
\hline
\end{tabular}

\section{Finite element model validation}

At first, the finite element model is validated considering the hydrostatic pressure parameter on the reservoir bottom by in terms of the boundary conditions obtained from analytical method. By performing static analysis of the model under gravity acceleration, the result has been obtained. Obtained result was compared with the result of analytical values to comprise the validity of the model. The hydrostatic pressure contour of the arch dam reservoir obtained from the finite element model has been shown in Figure 5.

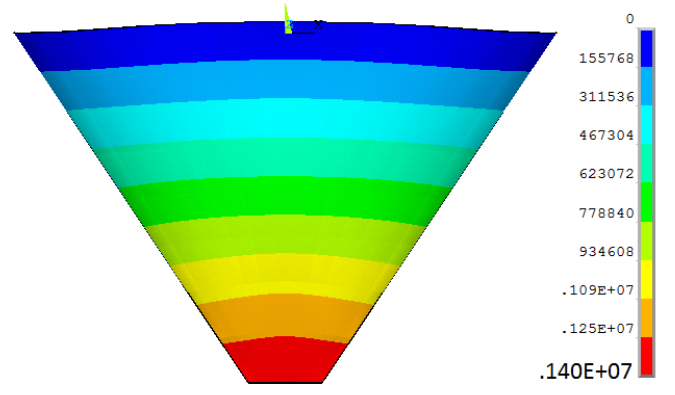

Figure 5. Hydrostatic pressure distribution of water inside the reservoir

The maximum value of hydrostatic pressure in the reservoir bottom is obtained according to the governing equation (4):

$$
P=\rho g h=1000 * 9.81 * 143=1402830 P a
$$

In which, $P$ is the hydrostatic pressure $(P a), \rho$ is the water density $\left(\mathrm{kg} / \mathrm{m}^{3}\right)$, and $\mathrm{h}$ is the height of the reservoir in meter. The comparison of the obtained results shows that the value obtained from the static analysis of the model did not differ much from the calculation of equation (4), so the finite element model has the appropriate accuracy. 


\section{Numerical analysis}

The dam-reservoir-foundation model is analyzed for two cases using the already discussed sensitivity and probabilistic methods. In the first case, the Young's modulus $\left(E_{c}\right)$ of the dam body concrete is chosen as the input parameter. For the second case, the modulus ratio $\left(E_{f} / E_{c}\right)$ is chosen as the input parameter. In the following, each study is evaluated individually. The results from both studies are provided by time history plots, cumulative distribution functions, and sensitivity plots. Figures 6 to 8 demonstrate the critical areas of the dam body for the Northridge and San-Fernando motions. The model is analyzed using the critical points of the dam body.

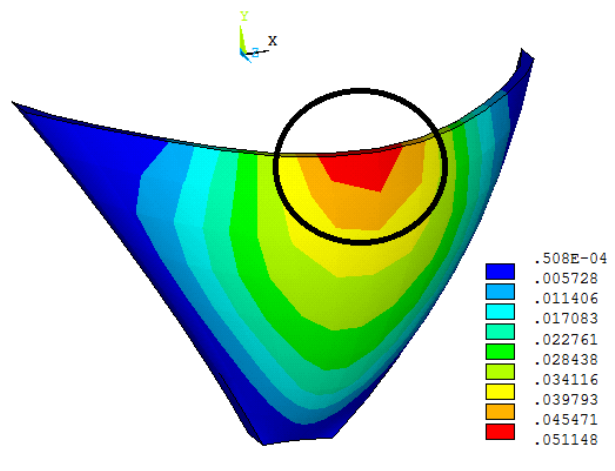

(a)

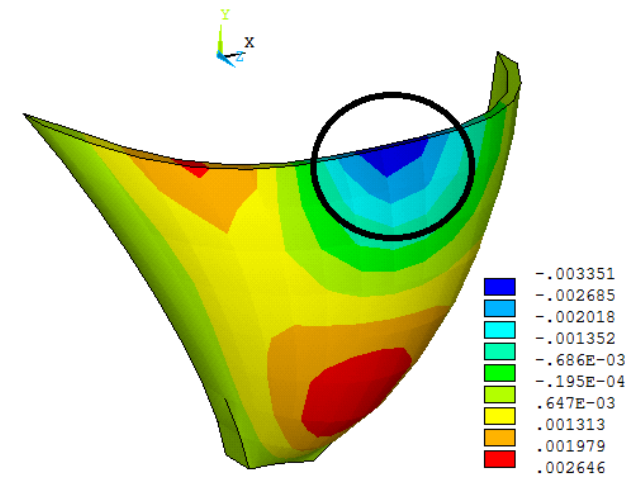

(b)

Figure 6. The critical areas of displacement of the dam crest (a) Northridge; (b) San-Fernando ground motion.

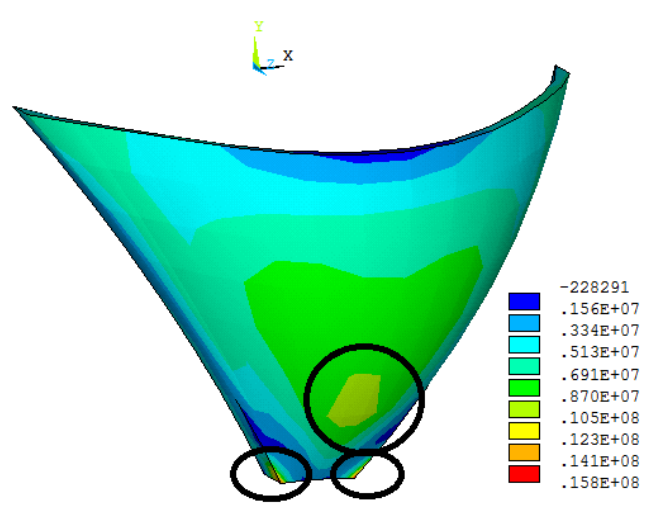

(a)

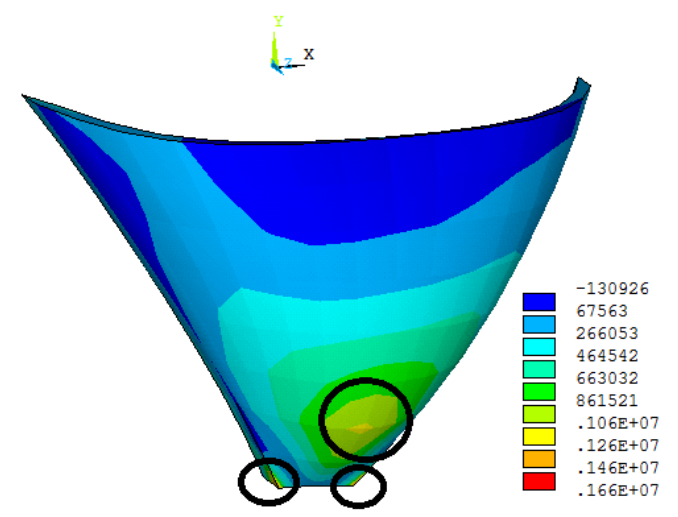

(b)

Figure 7. The critical areas of the $1^{\text {st }}$ principal stress for the (a) Northridge; (b) San-Fernando.
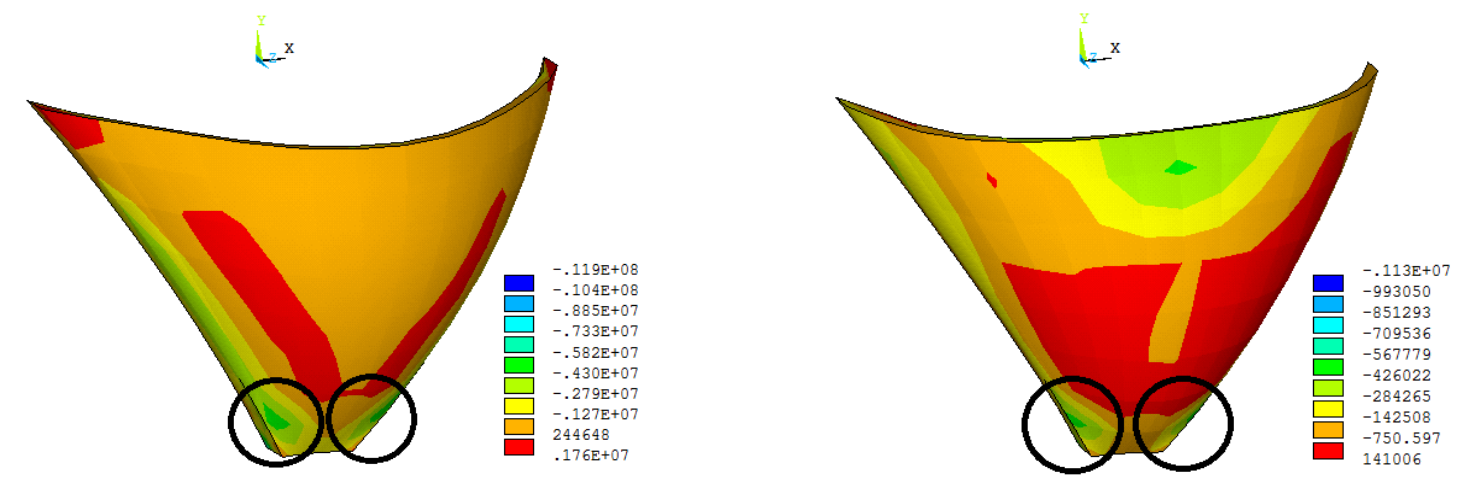
(a)

(b)

Figure 8. The critical areas of the $3^{\text {rd }}$ principal stress for the (a) Northridge; (b) San-Fernando ground motion.

\subsection{Evaluating the effects of concrete strength}

\subsubsection{Time history analysis}

Time histories of displacement of the dam crest along the river for the mid-point of the crest and the first and third principal stresses are provided in Figures 9 to 11, respectively.

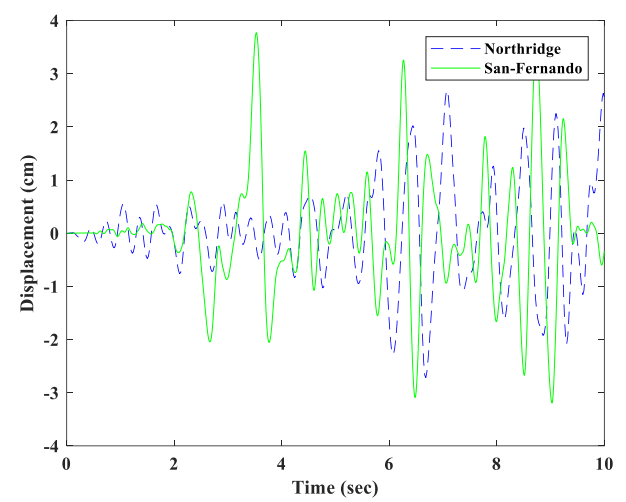

Figure 9. Time history of displacement of the dam crest along the river

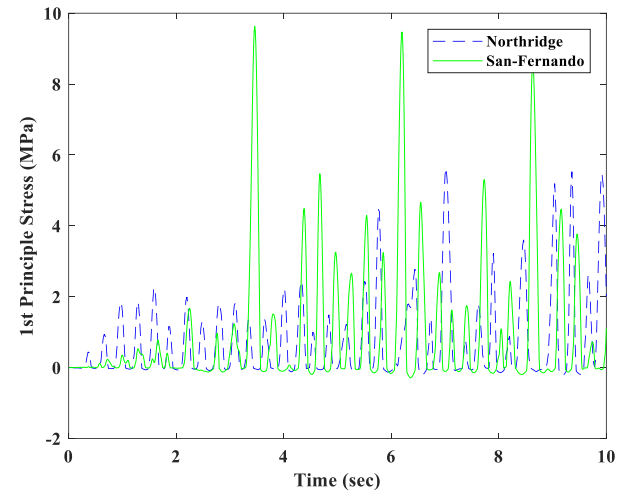

Figure 10. Time history of first principal stresses in the dam body 


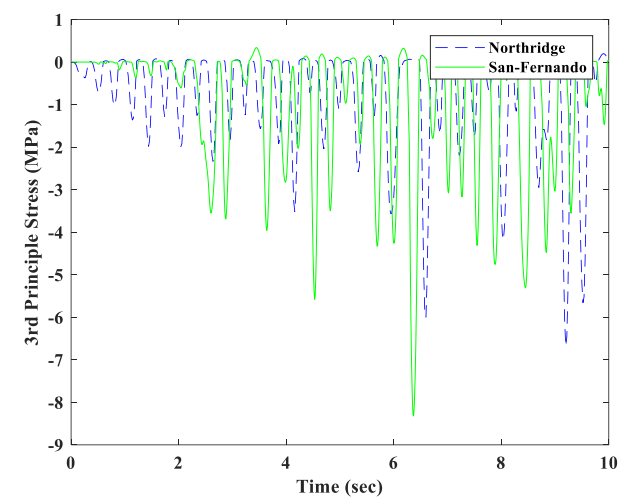

Figure 11. Time history of third principal stresses in the dam body

To better evaluate the effect of different earthquakes on the seismic response and compare the results, the numerical values of the critical responses from the time history analysis for selected ground motion are presented in Table 3 . It is clear that the maximum responses of both systems occur when the San-Fernando earthquake is applied.

Table 3. Maximum values of the responses from the time history analysis

\begin{tabular}{cccccc}
\hline \multicolumn{2}{l}{ Displacement $(\mathrm{cm})$} & \multicolumn{2}{c}{ 1st principal stress $(\mathrm{MPa})$} & \multicolumn{2}{c}{ 3rd principal stress $(\mathrm{MPa})$} \\
\hline Northridge & San-Fernando & Northridge & San-Fernando & Northridge & San-Fernando \\
\hline 2.68 & 3.77 & 5.64 & 9.63 & -6.68 & -8.32
\end{tabular}

6.1.2. Probabilistic and sensitivity analysis

The Young's modulus of the concrete used to construct the dam body has been selected as the input parameter for this stage of the analysis. The probabilistic analyses are intended to show how the input parameters affect the seismic analysis of the system. For the probability analysis method, 30 samples were selected for sensitivity analysis. Mean value plots are one of the best descriptions which to be found that modelling results are appropriate. Figure 12 displays the histogram of the variables versus the number of sample points.

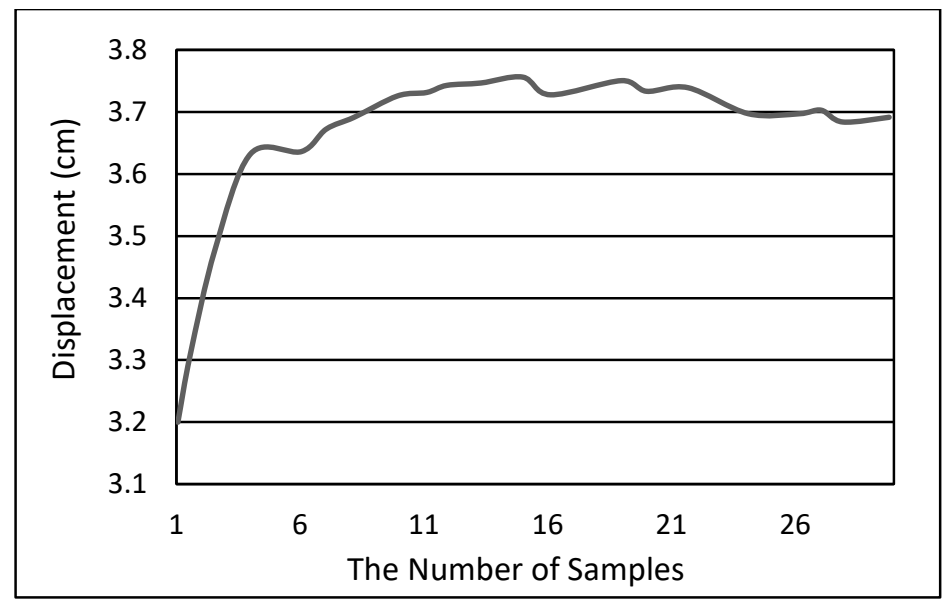

Figure 12. The Histogram of the displacement of dam crest along the river against the number of sample points. 
According to the figure 12 the end of curve was relatively flat; it shows that the number of simulations was adequate. The cumulative distribution function $(\mathrm{CDF})$ is obtained by integrating the probability density function and the value of CDF is the probability which indicates values below a specific value. Scatter plots showing the variation of output parameters with input variations are provided. Figures 13a, 14a and 15a show cumulative distribution function plots of the intended output parameters. The effects of input parameters on the variation of outputs are demonstrated in Figures 13b, 14b, and 15b.

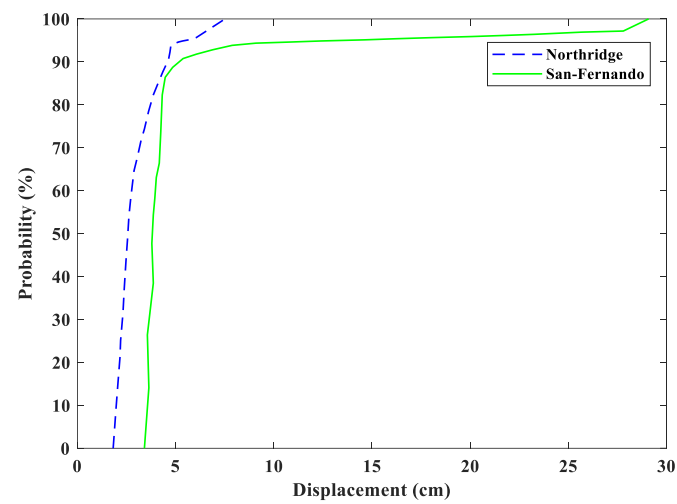

(a)

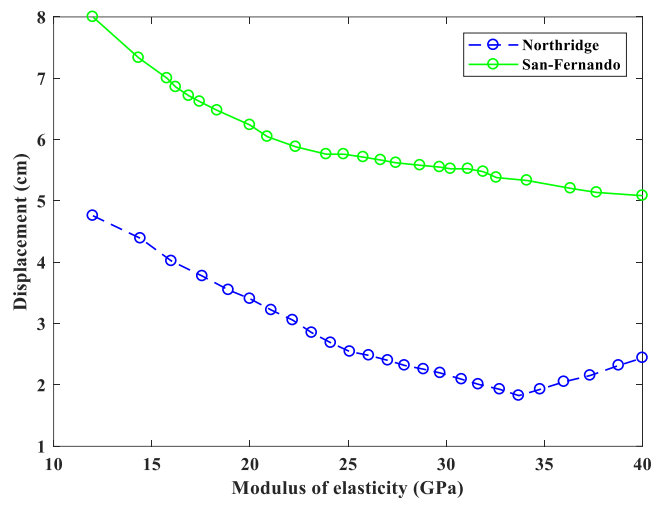

(b)

Figure 13. (a) The probability of displacement of the dam crest along the river for the applied earthquakes, (b) Sensitivity of displacement of the dam crest along the river to the modulus of elasticity.

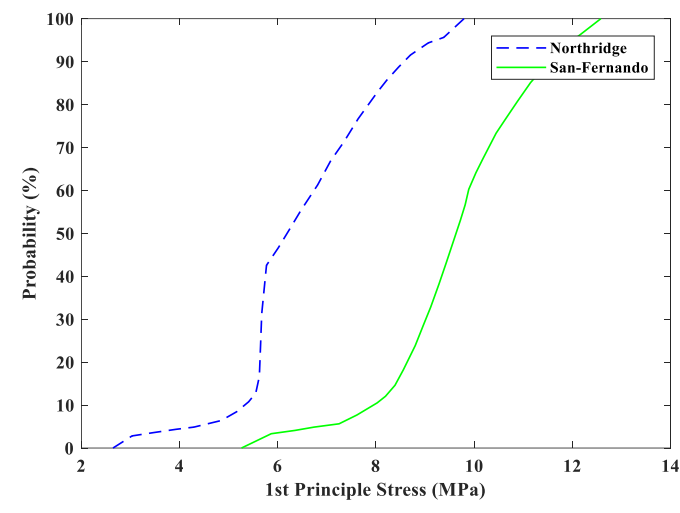

(a)

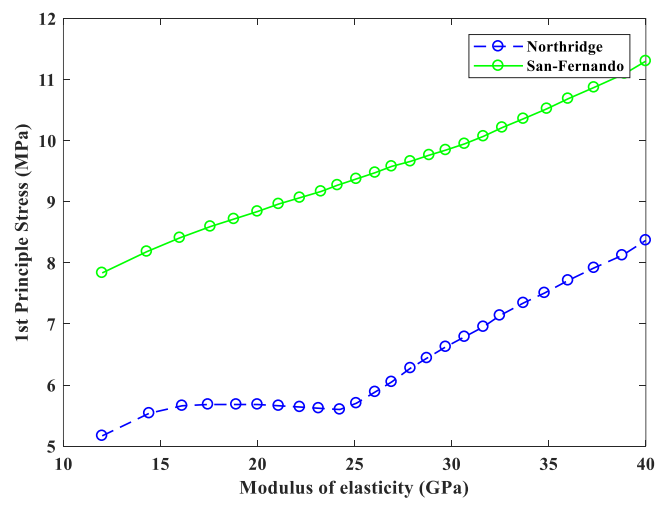

(b)

Figure 14. (a) The probability of 1st principal stresses for the applied earthquakes, (b) Sensitivity of the 1st principal stress to the modulus of elasticity.
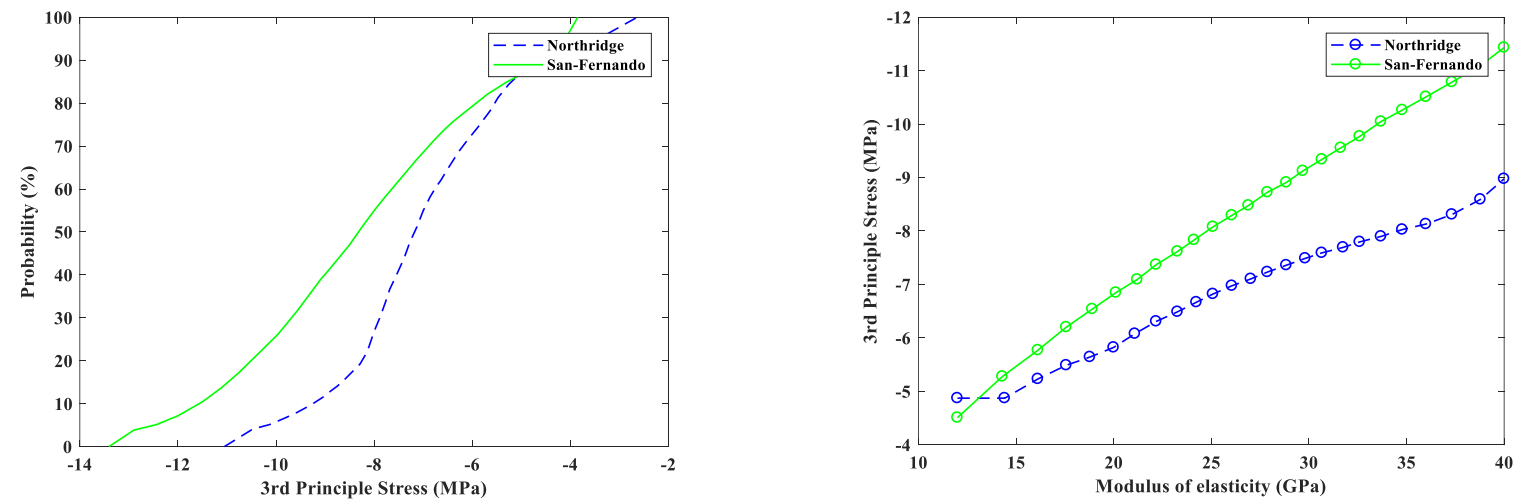
(a)

Figure 15. (a) The probability of 3rd principal stresses for the applied earthquakes, (b) Sensitivity of the 3rd principal stress to the modulus of elasticity

- According to ACI 318-14 (2015) and Raphael (1984), the allowable compressive and tensile strengths of concrete are 27.5MPa and 4.78MPa, respectively. Based on the results set forth in Figures 13a, 14a and 15a, there is about $90 \%$ probability that the displacement of the dam crest along the river will be less than $5 \mathrm{~cm}$.

- When subjected to the Northridge earthquake, there is about $10 \%$ probability that the $1^{\text {st }}$ principal stresses of the dam body will be below the allowable tensile strength. But for the model subjected to the San-Fernando earthquake, there is $100 \%$ probability that the $1^{\text {st }}$ principal stresses exceed the allowable tensile strength.

- There is about $100 \%$ probability for the $3^{\text {rd }}$ principal stresses of the dam body to be below the allowable compressive strength for the model subjected to either the Northridge or San-Fernando earthquakes.

The results in Figures 13b, 14b and 15b present the sensitivity of output parameters. It is clear that the various curves have differing slopes. The steep-sloped curves imply that the seismic responses of the system are more sensitive to the input parameter. It could be argued that the responses from both studies are more sensitive to the inputs when the San-Fernando earthquake is applied. According to the sensitivity analysis, it is concluded that the Young's modulus for the concrete of the dam body is an important parameter in the seismic analysis. Considering the relation between the Young's modulus of concrete and the seismic responses, a safe dam design can be found from this sensitivity analysis. In general, it can be concluded the seismic responses of the dam-reservoir-foundation system depend on various factors. For instance, the seismic behavior of the system is depending on the modulus of elasticity of the concrete and the earthquake ground motion.

\subsection{Evaluating the effects of modulus ratio changes}

\subsubsection{Time history analysis}

Time histories of displacement of the dam crest along the river at the critical mid-point of the crest and the first and third principal stresses at critical points of the dam body are demonstrated in Figures 16 to 18, respectively.

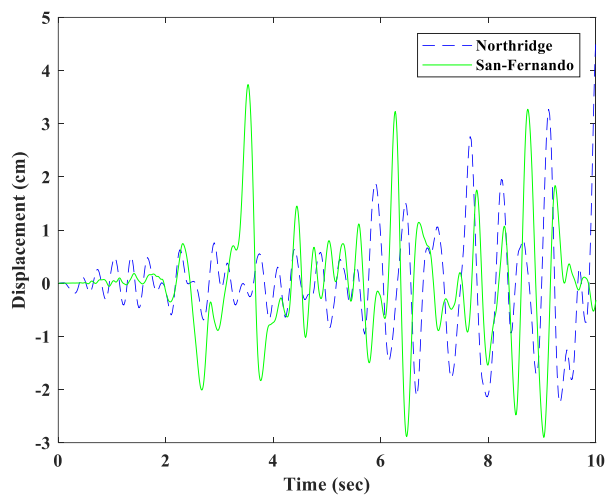

Figure 16. Time history of displacement of the dam crest along the river

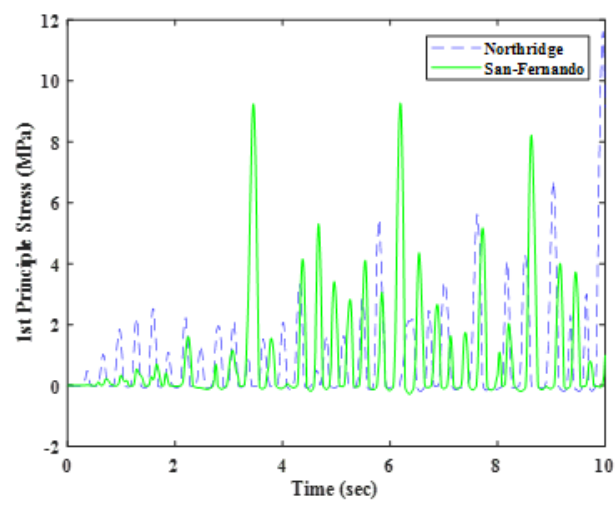

Figure 17. Time history of the first principal stress of dam body. 


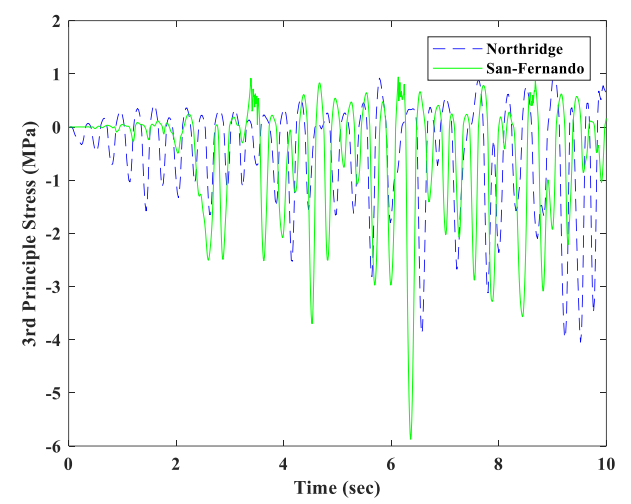

Figure 18. Time history of the third principal stress of dam body.

For this case, the numerical values of the maximum responses of critical points obtained from the time history analysis for selected ground motion are presented in Table 4.

Table 4. Maximum values of responses of time history analysis

\begin{tabular}{llllll}
\hline \multicolumn{2}{l}{ Displacement $(\mathrm{cm})$} & \multicolumn{2}{l}{ 1st principal stress $(\mathrm{MPa})$} & \multicolumn{2}{l}{ 3rd principal stress $(\mathrm{MPa})$} \\
\hline Northridge & San-Fernando & Northridge & San-Fernando & Northridge & San-Fernando \\
\hline 4.63 & 3.74 & 11.6 & 9.26 & -4.05 & -5.87 \\
\hline
\end{tabular}

As evident in Figures 16 to 18 and table 3, it is clear that the maximum displacement of the dam crest and the 1st principal stress occur when the Northridge earthquake is applied.

\subsubsection{Probabilistic and sensitivity analysis}

Here, modulus ratio of the foundation to concrete is the input parameter for the probability and sensitivity analyses. Figures 19a, 20a, and 21a show cumulative distribution function plots of the output parameters. The effects of input parameters on the variation of outputs are demonstrated in Figures 19b, 20b and 21b.

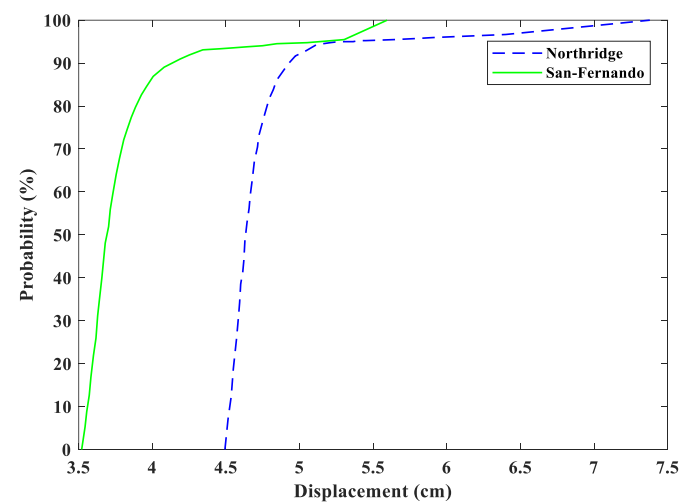

(a)

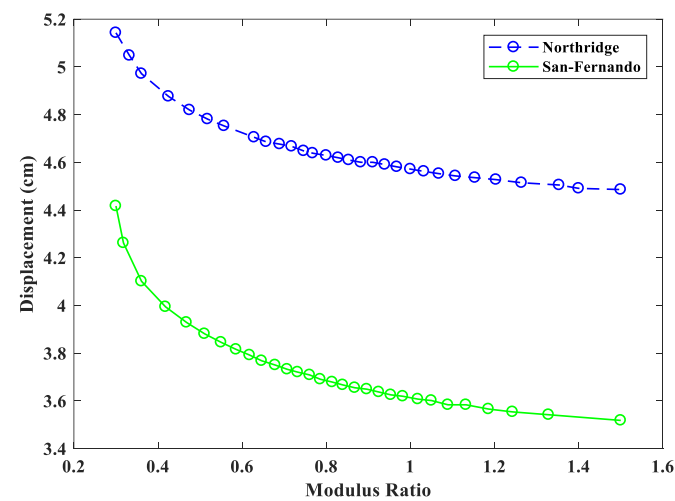

(b)

Figure 19. (a) The probability of displacements of the dam crest (b) Sensitivity of displacement of the dam crest to the modulus ratio 


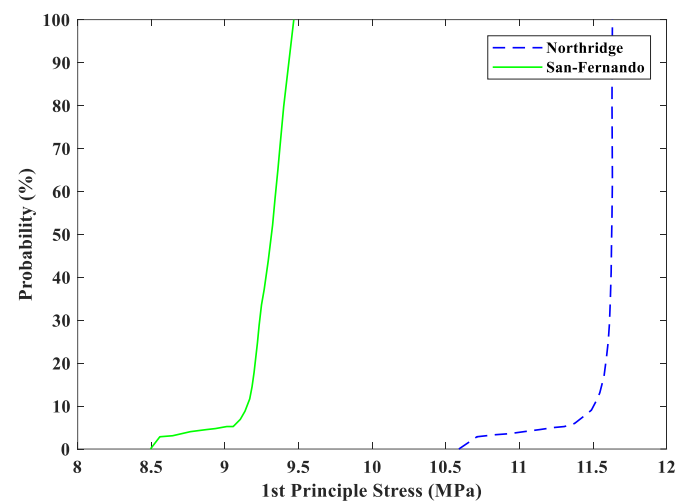

(a)

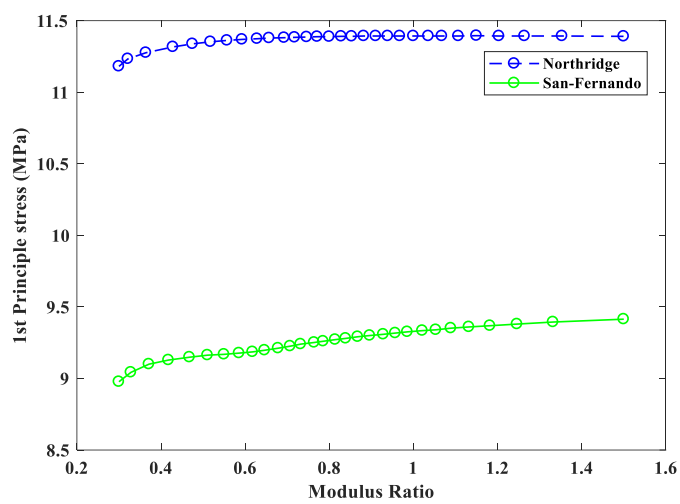

(b)

Figure 20. (a) The probability of the 1st principal stresses, (b) Sensitivity of the 1st principal stress to the modulus ratio

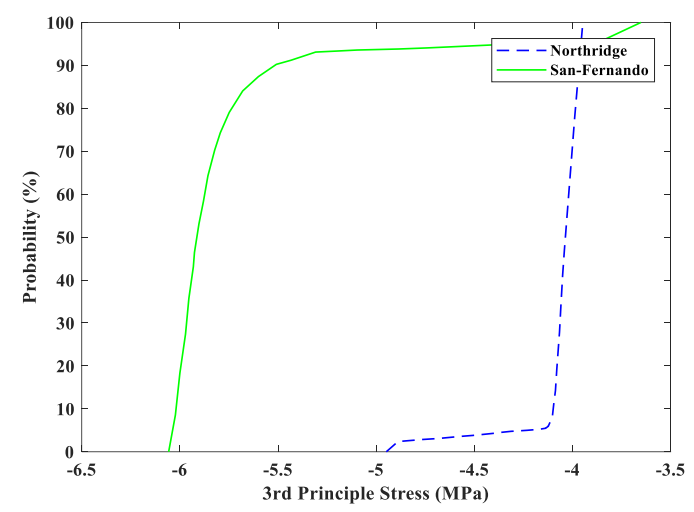

(a)

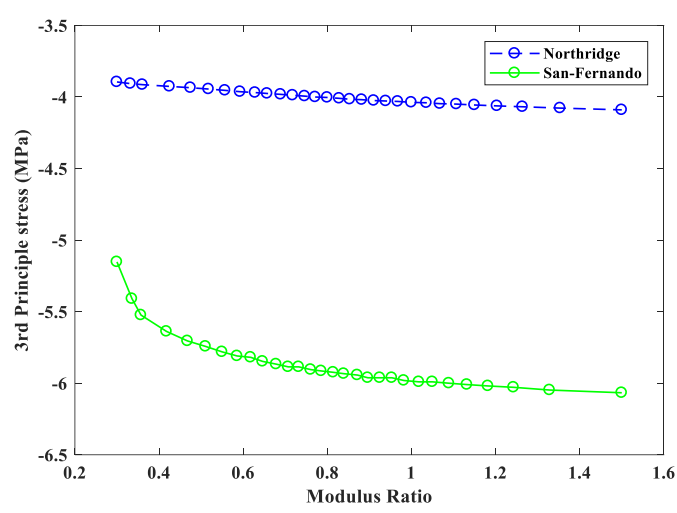

(b)

Figure 21. (a) The probability of the 3rd principal stresses, (b) Sensitivity of the 3rd principal stress to the modulus ratio

According to ACI 318-14 (2015) and Raphael (1984), the allowable compressive and tensile strengths of concrete were set to be $27.5 \mathrm{MPa}$ and $4.78 \mathrm{MPa}$, respectively. According to Figures 19a, 20a and 21a it can be concluded that:

- $\quad$ There is a $\sim 95 \%$ probability the displacement of the dam crest along the river to be less than $5.3 \mathrm{~cm}$.

- $\quad$ For both models subjected to the Northridge and San-Fernando earthquakes, there is a $100 \%$ probability that the $1^{\text {st }}$ principal stresses will exceed the allowed tensile strength.

- $\quad$ There is a $100 \%$ probability for remaining the $3^{\text {rd }}$ principal stresses of the dam body below the allowable compressive strength of both models which subjected to the Northridge and San-Fernando earthquakes.

The results in Figures 19b, 20b and 21b show the sensitivity and trends of the output parameters to variations of the inputs. The steep-sloped curves imply that the seismic responses of the system are more sensitive to the input parameter changes. It could be argued that the responses are more sensitive to input changes with the E4 earthquake particularly for low values of modulus ratio. As seen in figures, the displacement of the dam body is more sensitive to the variation of the modulus ratio under selected earthquakes, while the 1st principal stresses have less sensitivity for variation of modulus ratio. Also it can be considered that the sensitivity of 3rd principal stress of the dam body to variation of modulus ratio has different presentation under different ground motions.

Finally, it can be concluded that the sensitivity of responses is high for low values of modulus ratio. For high values of the ratio, the sensitivity of responses decrease and in this case, the foundation takes on a rigid behaviour.

\section{Conclusion}


It is evident that optimum parameters are essential for a proper design. In this paper, a finite element model of a MorrowPoint double curvature arch dam is analysed using a probabilistic method. The effects of Young's modulus and the modulus ratio are used as the output parameters. A Monte-Carlo simulation with Latin Hypercube sampling is utilized during the probabilistic analysis. To explore the effects of input parameters, certain output quantities were investigated. Those quantities include the displacement of the dam crest along the river, the 1st principal stress, and the 3rd principal stress. The results show that the Young's modulus of the concrete of the dam body can be effective for influencing the seismic behaviour of the model. Considering the relationship between Young's modulus and the seismic responses, the safe design of a dam can be determined based on a sensitivity analysis. Also, the results demonstrate that the sensitivity of the seismic behaviour to the modulus ratio changes. Based on the results, changes in the modulus of the elasticity of the dam body have a significant effect on the response values, and the response variations are large. Also the results show that the sensitivity of the responses is large for low value of the modulus ratio. For large values of the modulus ratio, the foundation yields a rigid performance and in this case the sensitivity of responses is not considerable.

These results depend on the material characteristics of the dam body and the foundation rock and applied earthquake contents. An optimal value is obtained for the modulus of elasticity $f$ to ensure system safety. It is recommended to use this type of study for large infrastructure systems. Following results were achieved according to the model analysis and sensitivity curves:

- Modulus of elasticity of concrete and Modulus ratio indicates the stiffness and strength of arch dam body and foundation, are important parameters in the analysis and design of system. Consider to the sensitivity curves of responses to variation of Modulus of elasticity it is possible to investigate the safety status of dam body for different value of these parameters.

- According to the graphs it is concluded that the sensitivity curves have different presentation for selected earthquakes. So, according to the sensitivity curves, the optimal value of parameters can be selected in a way that ensures the safety considering possible design earthquakes.

- Considering to sensitivity curves, it can be concluded that the maximum displacement of the dam body is more sensitive to the variation of the modulus ratio under selected earthquakes and the 1st principal stresses have less sensitivity. The sensitivity of 3rd principal stress of the dam body has different presentation under different ground motions.

Author contributions: Majid Pasbani Khiavi: Software, Methodology, Parya Ahamdi: Analysis and interpretation of data, Rasoul Daneshfaraz: Data curation, Conceptualization, John Abraham: Validation, Writing - original draft WritingReviewing and Editing.

Funding: The authors received no financial support for the research, authorship and publication of this article.

Conflicts of interest: All authors declare that they have no conflict of interest for the research.

References

Chopra, A. K. (2012). Earthquake analysis of arch dams: factors to be considered. Journal of Structural Engineering 138(2), 205-214.

Tan, H., \& Chopra, A. K. (1996) Dam-foundation rock interaction effects in earthquake response of arch dam, Journal of Structural Engineering, ASCE, $122(5), 528-538$.

Westergaard, H. M. (1933). Water pressures on Dams During Earthquakes, Transactions, American Society of Civil Engineers, 98.

Kuo, J. (1982). Fluid-structure Interactions: Added Mass Computations for Incompressible Fluid, University of California, College of Engineering, Earthquake Engineering Research Center.

Fok, K. L., \& Chopra, A. K. (1986). Hydrodynamic and foundation flexibility effects in earthquake response of arch dams, Journal of Structural Engineering. 112 (8), 1810-1828. 
Hariri-Ardebili, M. A., \& Mirzabozorg, H. (2013). Feasibility study of DEZ arch dam heightening based on nonlinear numerical analysis of existing dam, Archives of civil engineering, LIX-1, 21-49.

Heshmati, M., Hariri-Ardebili, M. A., Seyed Koldabi, S.M., \& Mirzabozorg, H. (2013). Are there any difference in seismic performance evaluation criteria for concrete arch dams, Civil engineering infrastructures journal, 46(2), 233-240.

National Academy Press, (1990). Earthquake Engineering for Concrete Dams: Design, Performance, and Research Needs, Panel on Earthquake engineering for Concrete Dams, Committee on Earthquake Engineering Division of Natural Hazard Mitigation, Commission on Engineering and Technical Systems, National Research Council.

Applied Technology Council (ATC), (2012). ATC-58: Guidelines for Seismic Performance Assessment of Buildings, Redwood City, CA, US.

Ferdousi, A., Gharabaghi, A.R. M., Ahmadi, M. T., Chenaghlou, M. R., \& Tabrizi, M. (2014). Earthquake analysis of arch dams including the effects of foundation discontinuities and proper boundary conditions, Journal of Theoretical and Applied Mechanics, 52(3), 579-594.

Leger, P., \& Boughoufalah, M. (1989). Earthquake input mechanisms for time-domain analysis of dam—-foundation systems, Engineering Structures, 11(1): $37-46$.

Altarejos, L., Bueno, I., \& Serrano-Lombillo, A. (2012). A Methodology for estimating the probability of failure by sliding in concrete gravity dams in the context of risk analysis, Structural Safety, 36-37, 1-13.

U.S. Environmental Protection Agency, (2014). Risk Assessment Forum White Paper: Probabilistic Risk Assessment Methods and Case Studies, Probabilistic Risk Analysis Technical Panel. Office of the Science Advisor.

Rohaninejad, M., \& Zarghami, M. (2012). Combining Monte Carlo and finite difference methods for effective simulation of dam behaviour, Advances in engineering software, 45, 197-202.

Cullen, A. C. , Frey, H. C. (1999). Probabilistic techniques in exposure assessment: a handbook for dealing with variability and uncertainty in models and inputs, Springer Science \& Business Media.

Morgan, M.G., Henrion, M., \& Small, M. (1992). Uncertainty: a Guide to dealing with uncertainty in quantitative risk and policy analysis, Cambridge University Press.

Risk assessment forum U.S. (1997). Environmental Protection Agency Washington, DC 20460, Risk assessment forum U.S, Guiding principal for Monte Carlo analysis.

McKay, M. D., Beckman, R. J., \& Conover, W. J. (2000). A comparison of three methods for selecting values of input variables in the analysis of output from a computer code, Technometrics, 42(1), 55-61.

Pasbani Khiavi, M., Ghorbani, M. A., \& Kouchaki, M. (2020). Evaluation of the effect of reservoir length on seismic behaviour of concrete gravity dams using Monte Carlo method, Numerical methods in civil engineering journal, 5(1), 1-7.

Pasbani Khiavi, M., Ghorbani, M. A., \& Ghaed Rahmati, A. (2020). Seismic Optimization of Concrete Gravity Dams Using a Rubber Damper, International Journal of Acoustics and Vibration, 25 (3), 425-435.

Pasbani Khiavi, M., Feizi, A., \& Ramzi, L. (2021). Effect of Strength Parameters on Seismic Performance of Elevated Tanks by Probabilistic Analysis, Journal of Hydraulic Structures, 7(1), 77-97.

Vamvatsikos, D., \& Fragiadakis, M. (2010). Incremental dynamic analysis for estimating seismic performance sensitivity and uncertainty, Earthquake Engineering and Structural Dynamics, 39, 141-163.

Chakrabati, P., \& Chopra, A.K. (1973). Earthquake analysis of gravity dams including hydrodynamic interaction, Earthquake Engineering and Structural Dynamics, 2, pp. 143-160.

Bathe, K . J. (1996). Finite element procedures, Upper Saddle River, New Jersey 07458.

Hall, J. F., \& Chopra, A. K. (1982). Hydrodynamic effects in the dynamic response of concrete gravity dams, Earthquake engineering and structural dynamics, $10,333-345$.

Sharan, S. K., \& Gladwell, G. M. L. (1985). A general method for the dynamic response analysis of fluid-structure systems, Computers and structures, 21, 937-943.

ACI Committee 318. Building Code Requirements for Structural Concrete (ACI 318-14), (2015). An ACI Standard: Commentary on Building Code Requirements for Structural Concrete (ACI 318R-14), an ACI Report. American Concrete Institute.

Raphael, J. M. (1984). Tensile strength of concrete, Journal Proceeding, 81(2), 158-165.

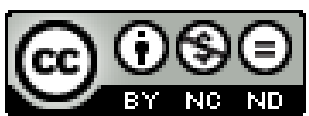
under a Creative Commons Attribution-Noncommercial-No Derivatives 4.0 International License. 